\title{
Peroxisome biogenesis disorder
}

INSERM

\section{Source}

INSERM. (1999). Orphanet: an online rare disease and orphan drug data base.

Peroxisome biogenesis disorder. ORPHA:79189

Peroxisome biogenesis disorders, Zellweger syndrome spectrum (PBD-ZSS) is a group of autosomal recessive disorders affecting the formation of functional peroxisomes, characterized by sensorineural hearing loss, pigmentary retinal degeneration, multiple organ dysfunction and psychomotor impairment, and is comprised of the phenotypic variants Zellweger syndrome (ZS), neonatal adrenoleukodystrophy (NALD) and infantile Refsum disease (IRD) (see these terms). 